\title{
Tracers for Fluorescence-Guided Surgery: How Elongation of the Polymethine Chain in Cyanine Dyes Alters the Pharmacokinetics of a Dual-Modality c[RGDyK] Tracer
}

\author{
Tessa Buckle ${ }^{1,2}$, Danny M. van Willigen ${ }^{1}$, Silvia J. Spa ${ }^{1}$, Albertus W. Hensbergen ${ }^{1}$, Steffen van der Wal ${ }^{1}$, Clarize M. de \\ Korne $^{1}$, Mick M. Welling ${ }^{1}$, Henk G. van der Poel ${ }^{3}$, James C.H. Hardwick ${ }^{4}$, and Fijs W.B. van Leeuwen ${ }^{1,3}$ \\ ${ }^{1}$ Interventional Molecular Imaging Laboratory, Department of Radiology, Leiden University Medical Center, Leiden, The \\ Netherlands; ${ }^{2}$ Division of Molecular Pathology, Netherlands Cancer Institute-Antoni van Leeuwenhoek Hospital, Amsterdam, \\ The Netherlands; ${ }^{3}$ Department of Urology, Netherlands Cancer Institute-Antoni van Leeuwenhoek Hospital, Amsterdam, The \\ Netherlands; and ${ }^{4}$ Department of Gastroenterology and Hepatology, Leiden University Medical Center, Leiden, The Netherlands
}

The potential of receptor-mediated fluorescence-based imageguided surgery tracers is generally linked to the near-infrared emission profile and good-manufacturing-production availability of fluorescent dyes. Surprisingly, little is known about the critical interaction between the structural composition of the dyes and the pharmacokinetics of the tracers. In this study, a dual-modality tracer design was used to systematically and quantitatively evaluate the influence of elongation of the polymethine chain in a fluorescent cyanine dye on the imaging potential of a targeted tracer. Methods: As a model system, the integrin marker $\alpha_{v} \beta_{3}$ was targeted using arginylglycylaspartisc acid [RGD]-based vectors functionalized with a ${ }^{111}$ In-diethylenetriaminepentaacetic acid (DTPA) chelate and a fluorescent dye: (Cy3- $\left(\mathrm{SO}_{3}\right)$ methyl- $\mathrm{COOH}$ [emission wavelength $\left.\left(\lambda_{\mathrm{em}}\right), 580 \mathrm{~nm}\right], \mathrm{Cy} 5-\left(\mathrm{SO}_{3}\right)$ methyl-COOH $\left[\lambda_{\mathrm{em}}, 680 \mathrm{~nm}\right]$, or Cy7-( $\left.\mathrm{SO}_{3}\right)$ methyl-COOH $\left.\left[\lambda_{\mathrm{em}}, 780 \mathrm{~nm}\right]\right)$. Tracers were analyzed for differences in photophysical properties, serum protein binding, chemical or optical stability, and signal penetration through tissue. Receptor affinities were evaluated using saturation and competition experiments. In vivo biodistribution (SPECT imaging and percentage injected dose per gram of tissue) was assessed in tumor-bearing mice and complemented with in vivo and ex vivo fluorescence images obtained using a clinical-grade multispectral fluorescence laparoscope. Results: Two carbon-atom-step variations in the polymethine chain of the fluorescent cyanine dyes were shown to significantly influence the chemical and photophysical characteristics (e.g., stability, brightness, and tissue penetration) of the hybrid RGD tracers. DTPA-Cy5-( $\left.\mathrm{SO}_{3}\right)$ methyl- $\mathrm{COOH}-\mathrm{c}[\mathrm{RGDyK}]$ structurally outperformed its Cy3 and Cy7 derivatives. Radioactivity-based evaluation of in vivo tracer pharmacokinetics yielded the lowest nonspecific uptake and highest tumor-to-background ratio for DTPA-Cy5-( $\left(\mathrm{SO}_{3}\right)$ methyl-COOH-c[RGDyK] (13.2 \pm 1.7$)$, with the Cy 3 and Cy 7 analogs trailing at respective tumor-to-background ratios of $5.7 \pm 0.7$ and $4.7 \pm 0.7$. Fluorescence-based assessment of tumor visibility revealed a similar trend. Conclusion: These findings underline that variations in the polymethine chain lengths of cyanine dyes have a profound influence on the photophysical properties, stability, and in vivo targeting capabilities of fluorescent imaging tracers. In a direct comparison, the intermediate-length

Received Nov. 17, 2017; revision accepted Jan. 12, 2018.

For correspondence or reprints contact: Fijs W.B. van Leeuwen, Interventional Molecular Imaging Laboratory, Department of Radiology, Leiden University Medical Center, Albinusdreef 2, C2-S zone, P.O. Box 9600, 2300 RC, Leiden, The Netherlands.

E-mail: f.w.b.van_leeuwen@lumc.nl

Published online Feb. 15, 2018.

COPYRIGHT (c) 2018 by the Society of Nuclear Medicine and Molecular Imaging. dye (Cy5) yielded a superior c[RGDyK] tracer, compared with the shorter (Сy3) and longer (Cy7) analogs.

Key Words: fluorescence; dual-modality; bimodal; hybrid; fluorescence-guided surgery; cyanine dyes

J Nucl Med 2018; 59:986-992

DOI: 10.2967/jnumed.117.205575

W

ithin the nuclear medicine community, structural optimization of receptor-targeted radiotracers is a common good. Specific attention is paid to the influence of radiolabeling methods on the tracer pharmacokinetics (1). When the generation of fluorescence tracers is being pursued, however, the limited ability to quantify fluorescence tracer distribution (2) means that such studies are often ignored. As a result, fluorescent tracers are being transferred to clinical trials without knowledge or reporting of the whole-body kinetics (3-6). By including radiolabels on fluorescence tracers, so-called dual-modality (bimodal or hybrid) tracers are generated that allow quantitative mapping of the pharmacokinetic properties (7). This concept has been successfully applied to nanoparticles, antibody analogs, and peptides (8-13), as exemplified by the plurality of hybrid tracers in the literature (14-17). For example, for the arginylglycylaspartic acid (RGD) vector, it has been documented that the introduction of different pendant moieties on an otherwise stable conjugated system influences the pharmacokinetics (18-22).

The theoretic argument that near-infrared fluorescence emissions (emission wavelength $\left[\lambda_{\mathrm{em}}\right], \geq 750 \mathrm{~nm}$ ) provide superior tissue penetration has driven the use of reactive dyes such as indocyanine green (ICG)-OSu, ZW800, and IRDye 800CW $(1,23,24)$. When these dyes are used to functionalize a targeting vector, their tendency to stack, chemical instability, low fluorescence brightness, or relatively large size are generally not considered (25-27). Preclinical and clinical studies indicate that the in-depth fluorescence imaging properties of slightly smaller farred dyes (e.g., the cyanine dye Cy5; $\lambda_{\mathrm{em}}, 650-750 \mathrm{~nm}$ ) also support in vivo applications (28-30), including fluorescence-guided surgery $(3,31)$. In addition to providing an alternative to the use of near-infrared dyes, adoption of other fluorescence wavelengths also creates the potential for a multiparametric image-guidance 
process that supports the detection of two or more fluorescent features in one patient $(29,32)$.

In the unique design of cyanine dyes, wherein the length of the polymethine chain that bridges the two indole units (being 3, 5, and 7 carbon atoms long in $\mathrm{Cy} 3, \mathrm{Cy} 5$, and $\mathrm{Cy} 7$, respectively) dictates the spectral properties of the dye. This feature allows the creation of fluorescent tracers of which the spectral properties can be specifically tuned for use alongside tracers of different wavelengths. Whereas dye optimization currently focuses on optimization of pendant moieties on cyanine dyes $(18,33)$, the influence of alterations in the length of the polymethine chain has not yet been reported. To isolate the influence of the length of the polymethine chain on overall tracer performance, the performance of a previously optimized $\mathrm{Cy} 5$ dye $\left(\mathrm{Cy} 5-\left(\mathrm{SO}_{3}\right)\right.$ methyl$\mathrm{COOH}$ ) (18) was systematically compared with its $\mathrm{Cy} 3$ and $\mathrm{Cy} 7$ analogs with identical pendant moieties. A hybrid RGD-tracer design (Fig. 1) was used to directly link detailed evaluation of the chemical properties (synthesis and chemical stability) and photophysical properties (brightness and optical stability) of these three tracers to their respective biologic properties (in vitro, in vivo, and ex vivo) and imaging capabilities.

\section{MATERIALS AND METHODS}

The Cy3, Cy5, and Cy7 dyes and corresponding hybrid RGD peptides were prepared and photophysically analyzed in line with previous reports $(18,34-37)$. Determination of photophysical properties and of stability $(18,27,36,38)$, receptor affinity (15), and fluorescence confocal imaging (15) was performed as previously described.

The 4T1 tumor model was generated as previously described $(15,18,39)$. All animal experiments were in accordance with Dutch welfare regulations and were approved by the local ethics committee of the Leiden University Medical Center.

\section{Isotope-Based Assessment of In Vivo Tracer Distribution}

Radiolabeling of the diethylenetriaminepentaacetic acid (DTPA) functionalized tracers DTPA-Cy3-( $\left.\mathrm{SO}_{3}\right)$ methyl-COOH-c[RGDyK], DTPA-Cy5-( $\left(\mathrm{SO}_{3}\right)$ methyl-COOH-c[RGDyK], and DTPA-Cy7- $\left(\mathrm{SO}_{3}\right)$ methyl-COOH-c[RGDyK] with ${ }^{111} \mathrm{InCl}_{3}$ and subsequent assessment of labeling accuracy was performed as described previously (18), using about $1 \mathrm{MBq}$ for biodistribution $(n=4)$ and $10-20 \mathrm{MBq}$ for SPECT imaging $(n=2)$, followed by ex vivo evaluation of the biodistribution (in total, 6 animals per tracer). Imaging of 4T1 tumor- bearing mice was performed on a U-SPECT scanner (MILabs) according to previously described methods $(18,39)$.

Quantitative biodistribution (percentage injected dose per gram of tissue $[\% \mathrm{ID} / \mathrm{g}]$ and tumor-to-background ratio [T/B] [tumor-to-muscle $\% \mathrm{ID} / \mathrm{g}]$ ) were measured $24 \mathrm{~h}$ after injection and analyzed with a relative performance scoring based on previously described procedures (18).

\section{In Vivo Fluorescence Imaging}

The mice were sacrificed after SPECT imaging, followed by fluorescence imaging performed using a preclinical IVIS Spectrum system (Caliper Life Sciences) and a clinical-grade laparoscope setup (Storz Endoskope GMBh) that allows multispectral imaging (30).

On the preclinical system, in vivo and ex vivo images of mice and excised tissues were acquired at Cy3 (excitation wavelength $\left[\lambda_{\mathrm{ex}}\right], 535$ $\left.\mathrm{nm} ; \lambda_{\mathrm{em}}, 580 \mathrm{~nm}\right)$, Cy5 $\left(\lambda_{\mathrm{ex}}, 640 \mathrm{~nm} ; \lambda_{\mathrm{em}}, 680 \mathrm{~nm}\right)$, and Cy7 ( $\lambda_{\mathrm{ex}}, 745$ $\mathrm{nm} ; \lambda_{\mathrm{em}}, 780 \mathrm{~nm}$ ) settings. Quantitative analysis of the fluorescence in the tissues (photons $/ \mathrm{s} / \mathrm{cm}^{2}$ ) and the T/B ratio was performed using the Living Image software, version 3.2 (Caliper Life Sciences). For imaging with the fluorescence laparoscope, mice were placed on top of an adjustable lift and imaged with a setup identical to that used to evaluate the signal penetration of the fluorescent emissions (28-30). Images were acquired using a clinical-grade IMAGE $1 \mathrm{~S}$ camera equipped with a $0^{\circ}$ laparoscope. Excitation was achieved using a DLight C light source (autofluorescence/fluorescein), a Cy5-modified D-Light C light source (Cy5), and a prototype D-Light P light source (ICG) (all Karl Storz). Built-in emission filters for Cy3 (autofluorescence mode) and Cy7 (ICG mode; catalog no. 26003AGA; Karl Storz) were used for detection of either Cy3 or Cy7. Cy5 was detected by placement of an additional standard eyepiece adaptor (catalog no. 20100034; Karl Storz) between the camera and the laparoscope (30).

\section{Statistical Data Analysis}

Analytic data were expressed as mean $\pm \mathrm{SD}$ as calculated using Microsoft Excel software. The significance of 2 mean values was calculated using a Student $t$ test. The level of significance was set at a $P$ value of 0.05 .

\section{RESULTS}

\section{Synthesis of CyX-( $\left.\mathrm{SO}_{3}\right)$ Methyl-COOH Dyes and DTPA-CyX- c[RGDyK] Tracers}

The ease of synthesis was highest for Cy5-( $\left.\mathrm{SO}_{3}\right)$ methyl-COOH. Although $\mathrm{Cy} 7-\left(\mathrm{SO}_{3}\right)$ methyl- $\mathrm{COOH}$ could also be synthesized

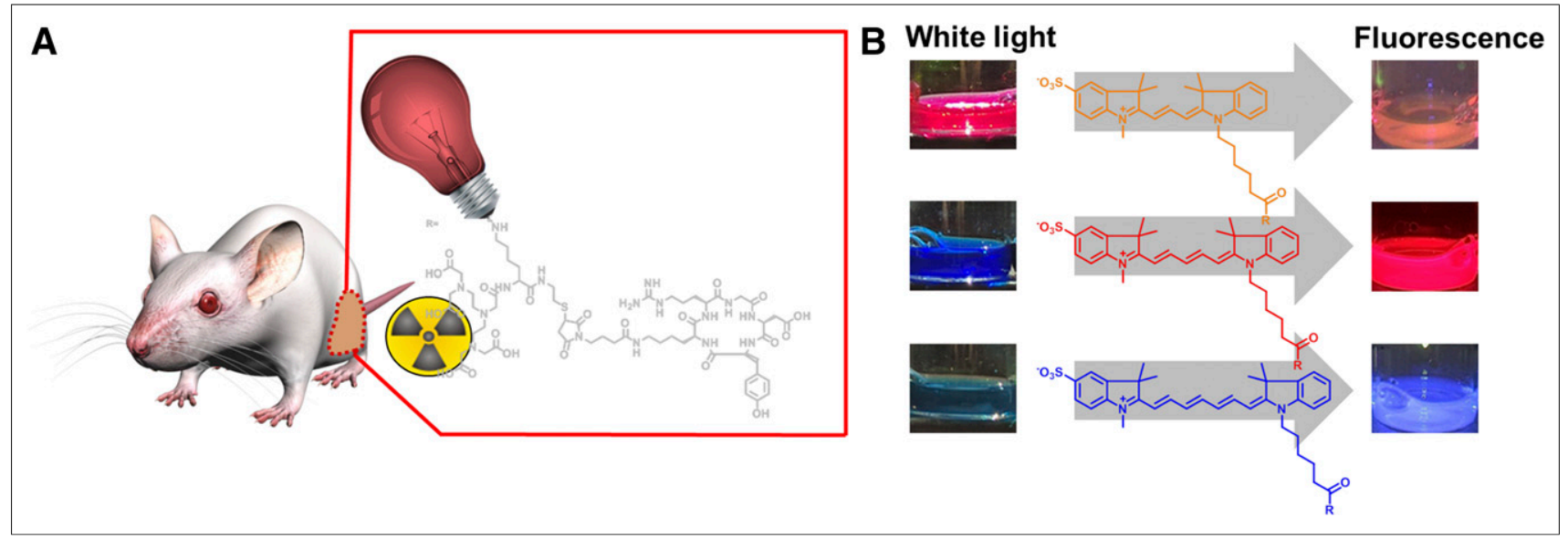

FIGURE 1. (A) Schematic visualization of mouse in which tumor is illuminated by hybrid c[RGDyK] tracer. (B) The 3 different cyanine dyes (Cy3 in orange, Cy5 in red, and Cy7 in blue) and their visible and fluorescence colorations as depicted by Karl Storz laparoscopic setup. 
TABLE 1

Photophysical Properties of Hybrid c[RGDyK] Tracers

\begin{tabular}{|c|c|c|c|}
\hline Property & $\begin{array}{l}\left.\text { DTPA-Cy3-( } \mathrm{SO}_{3}\right) \text { methyl- } \\
\text { COOH-c[RGDyK] }\end{array}$ & $\begin{array}{l}\left.\text { DTPA-Cy5-( } \mathrm{SO}_{3}\right) \text { methyl- } \\
\text { COOH-c[RGDyK] }\end{array}$ & $\begin{array}{l}\text { DTPA-Cy7-(}\left(\mathrm{SO}_{3}\right) \text { methyl- } \\
\mathrm{COOH}-\mathrm{c}[\mathrm{RGDyK}]\end{array}$ \\
\hline $\begin{array}{l}\lambda_{\text {ex }} / \lambda_{\text {em }} \text { in } \mathrm{H}_{2} \mathrm{O} \text { and PBS } \\
\text { (Stokes shift) }\end{array}$ & $547 / 565(18 \mathrm{~nm})$ & 644/663 (19 nm) & $745 / 770(25 \mathrm{~nm})$ \\
\hline $\begin{array}{l}\lambda_{\mathrm{ex}} / \lambda_{\mathrm{em}} \text { in albumin }(200 \mathrm{mg} / \mathrm{mL}) \\
\text { (Stokes shift) }\end{array}$ & $552 / 570(18 \mathrm{~nm})$ & 653/668 (15 nm) & $761 / 779(18 \mathrm{~nm})$ \\
\hline$\Phi_{\mathrm{F}}$ in PBS & $3 \%{ }^{*}$ & $19 \%^{\dagger}$ & $11 \% \ddagger$ \\
\hline$\Phi_{\mathrm{F}}$ in albumin $(200 \mathrm{mg} / \mathrm{mL})$ & $6 \% \pi$ & $23 \% \pi$ & $12 \% \pi$ \\
\hline \multicolumn{4}{|l|}{ Brightness relative to Сy3 } \\
\hline PBS & 1 & 6 & 42 \\
\hline Albumin & 1 & 4 & \\
\hline Calculated $\log \mathrm{D}^{\S}$ & -18.02 & -17.49 & -16.96 \\
\hline \multicolumn{4}{|c|}{ 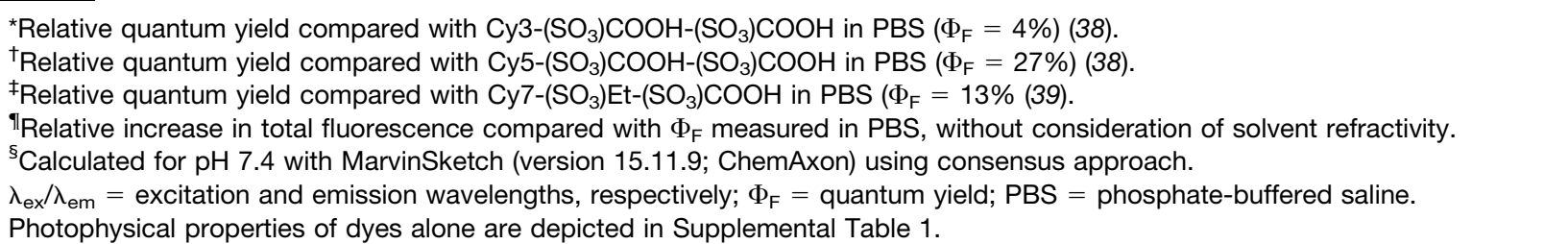 } \\
\hline
\end{tabular}

using a good-manufacturing-production-compatible solid support (see supplemental materials, available at http://jnm.snmjournals. org), reduced reactivity of the reagent for the elongated polymethine chain was observed. The preparation of $\mathrm{Cy} 3-\left(\mathrm{SO}_{3}\right)$ methyl$\mathrm{COOH}$ was most complex, probably because of the increased tendency of $\mathrm{Cy} 3$ (or trimethine) dyes to exist in the cis-state. In thermodynamic terms, that causes unfavorable steric influences (40). Conjugation of the dyes to the DTPA-containing dipeptide again was most efficient for Cy5; a 25\% yield was achieved for DTPA-Cy5( $\left.\mathrm{SO}_{3}\right)$ methyl-COOH-c[RGDyK], whereas DTPA-Cy5-( $\left.\mathrm{SO}_{3}\right)$ methyl$\mathrm{COOH}-\mathrm{c}[\mathrm{RGDyK}]$ and DTPA-Cy7-( $\left.\mathrm{SO}_{3}\right)$ methyl-COOH-c[RGDyK] conveyed only a $10 \%$ and $19 \%$ yield, respectively.

\section{Photophysical Properties of the Dyes and Complete Tracers}

Differences in photophysical properties were observed between the hybrid c[RDGyK] tracers (Table 1 (36,38); Supplemental Fig. 1) and between the hybrid tracers and the unconjugated dyes (Fig. 2; Supplemental Fig. 2; Supplemental Table 1). Absorption and emission were slightly lower for $\mathrm{Cy} 7-\left(\mathrm{SO}_{3}\right)$ methyl-COOH than for the reference dye ICG (Supplemental Fig. 3A).

Perhaps most striking was the variation in the quantum yield, in which the order of superiority was DTPA-Cy5-( $\left.\mathrm{SO}_{3}\right)$ methyl-COOHc[RGDyK] (19\%) > DTPA-Cy7-( $\left.\mathrm{SO}_{3}\right)$ methyl-COOH-c[RGDyK] $(11 \%)>$ DTPA-Cy3-( $\left.\mathrm{SO}_{3}\right)$ methyl-COOH-c[RGDyK] $(3 \%)$, as well as $\mathrm{Cy} 5-\left(\mathrm{SO}_{3}\right)$ methyl-COOH-SH $(13 \%)>\mathrm{Cy} 7-\left(\mathrm{SO}_{3}\right)$ methyl-COOH$\mathrm{SH}(9 \%)>\mathrm{Cy} 3-\left(\mathrm{SO}_{3}\right)$ methyl-COOH-SH $(1 \%)$. The steric promotion to the less favorable cis-isomer significantly impaired the quantum yield of DTPA-Cy3-( $\left.\mathrm{SO}_{3}\right)$ methyl-COOH-SH and Cy3-( $\left.\mathrm{SO}_{3}\right)$ methyl$\mathrm{COOH}-\mathrm{SH}$ (Fig. 2; Supplemental Figs. 1 and 2; Table 1; Supplemental Table 1) (41).

\section{Serum Protein Binding}

Serum protein binding studies with the unconjugated dyes and the hybrid c[RGDyK] tracers (Fig. 3A) revealed a $40 \%$ decrease in serum binding for DTPA-Cy5-( $\left.\mathrm{SO}_{3}\right)$ methyl-COOH-c[RGDyK] compared with the unconjugated $\mathrm{Cy} 5$ derivative (36\% vs. $76 \%$ ).
A similar effect was observed for DTPA-Cy7-( $\left.\mathrm{SO}_{3}\right)$ methyl-COOH$\mathrm{c}[\mathrm{RGDyK}]$, for which serum binding decreased by $34 \%$ within the hybrid construct $(55 \%$ vs. $89 \%)$. For DTPA-Cy3- $\left(\mathrm{SO}_{3}\right)$ methyl$\mathrm{COOH}-\mathrm{c}[\mathrm{RGDyK}](55 \%)$, no clear differences were seen between the hybrid tracer and the unconjugated $\mathrm{Cy} 3$ derivative (58\%).

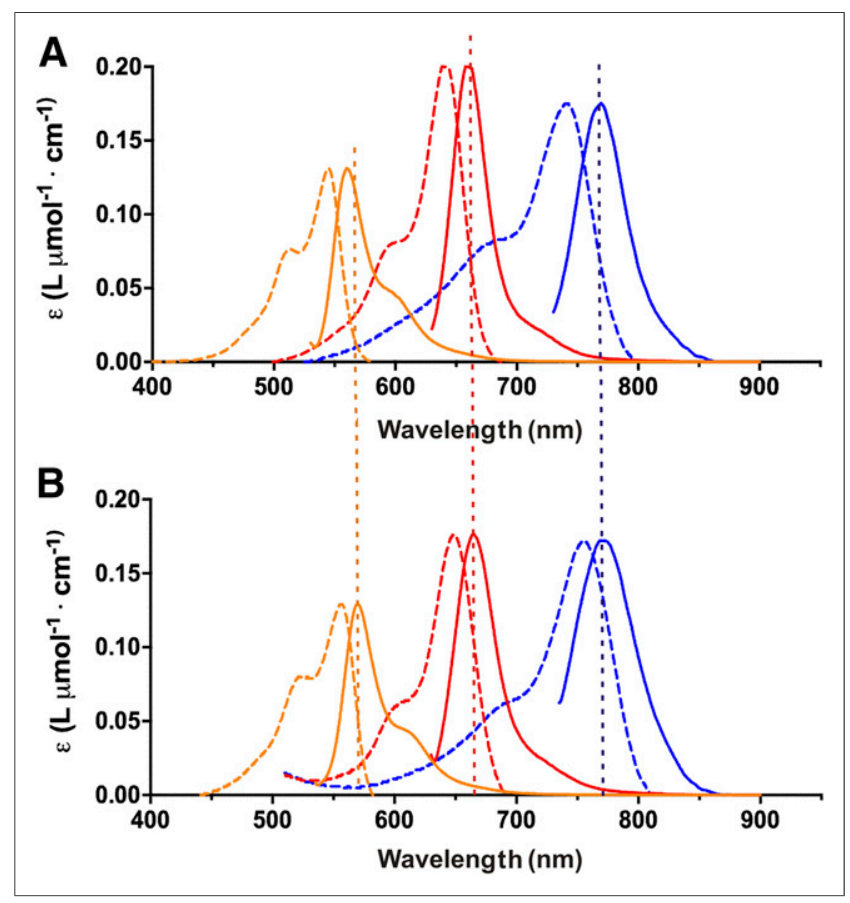

FIGURE 2. Photophysical properties of $\left(\mathrm{SO}_{3}\right)$ methyl- $\mathrm{COOH}$ dyes. $\mathrm{Ab}-$ sorption and emission spectra of $\mathrm{Cy} 3-\left(\mathrm{SO}_{3}\right)$ methyl-COOH (orange), Cy5$\left(\mathrm{SO}_{3}\right)$ methyl- $\mathrm{COOH}$ (red), and Cy7-( $\left.\mathrm{SO}_{3}\right)$ methyl- $\mathrm{COOH}$ (blue) in phosphatebuffered saline (A) and in $200 \mathrm{mg} / \mathrm{mL}$ solution of albumin in water (B). Dotted lines reveal red-shift in emission after addition of albumin. Photophysical properties of hybrid tracers are provided in Supplemental Figure 1. 


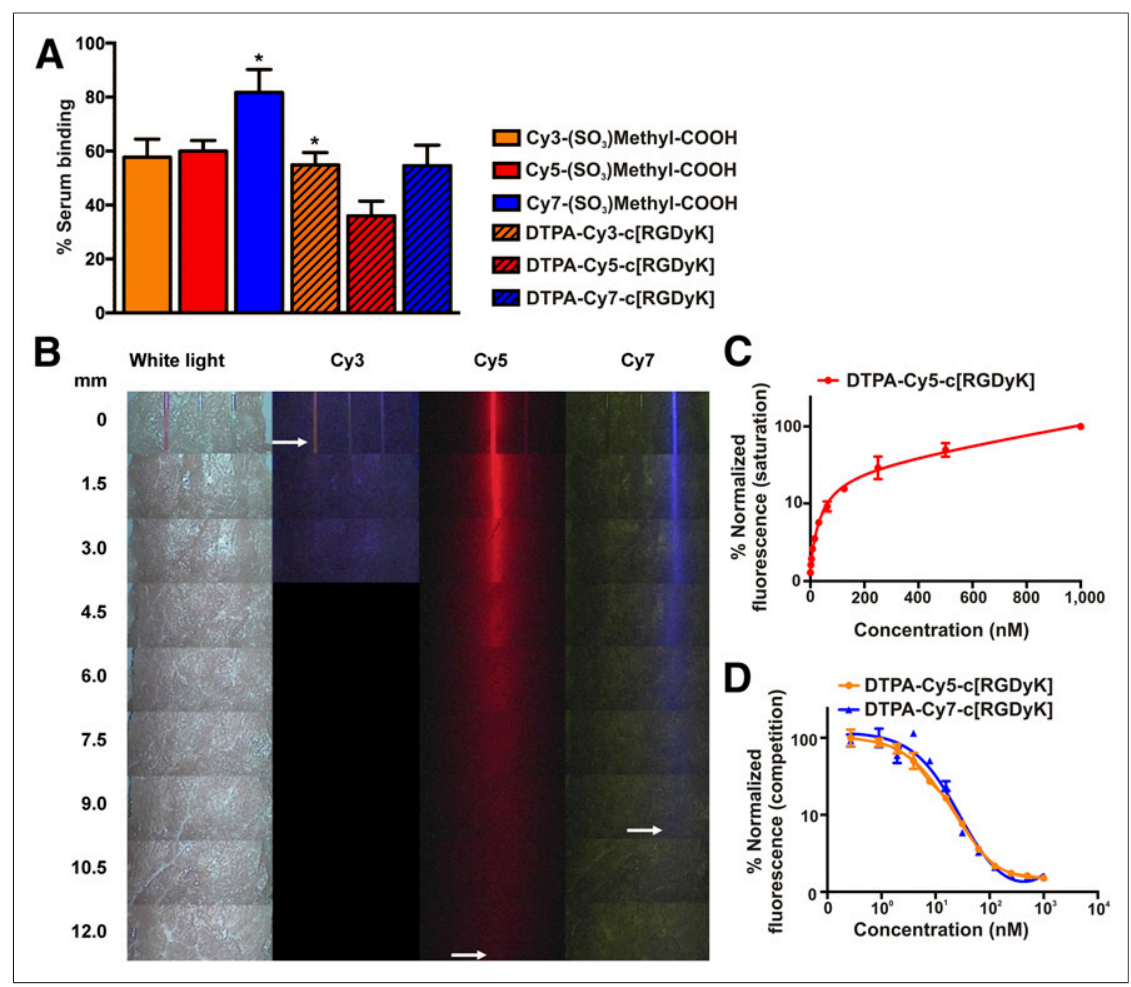

FIGURE 3. Protein binding, tissue penetration, and receptor affinity. (A) Protein binding in serum of free CyX-( $\left.\mathrm{SO}_{3}\right)$ methyl-COOH dyes and DTPA-CyX-( $\left.\mathrm{SO}_{3}\right)$ methyl-COOH-c[RGDyK] tracers (DTPA-CyX-c[RGDyK], dashed bars; $\left.{ }^{*} P<0.005\right)$. (B) Tissue penetration of Cy3-( $\left.\mathrm{SO}_{3}\right)$ methyl$\mathrm{COOH}$ (orange), Cy5-( $\left.\mathrm{SO}_{3}\right)$ methyl- $\mathrm{COOH}$ (red), and $\mathrm{Cy} 7-\left(\mathrm{SO}_{3}\right)$ methyl- $\mathrm{COOH}$ (blue), diluted in albumin and measured with clinical-grade laparoscopic fluorescence camera. (C) Saturation binding curve of DTPA-Cy5-( $\left.\mathrm{SO}_{3}\right)$ methyl-COOH-c[RGDyK]. (D) Competition binding curves of DTPA-Cy3-( $\left.\mathrm{SO}_{3}\right)$ methyl-COOH-c[RGDyK] and DTPA-Cy7-( $\left.\mathrm{SO}_{3}\right)$ methyl-COOH-c[RGDyK].

\section{Stability of Unconjugated Dyes and Hybrid Tracers}

Assessment of the fluorescence intensity before and after 30 min of excitation revealed a good photostability for both DTPACy3- $\left(\mathrm{SO}_{3}\right)$ methyl-COOH-c[RGDyK] and DTPA-Cy5-( $\left.\mathrm{SO}_{3}\right)$ methyl$\mathrm{COOH}-\mathrm{c}[\mathrm{RGDyK}]$, as the intensity loss for both tracers remained below 14\% (Supplemental Fig. 4). For DTPA-Cy7-( $\left.\mathrm{SO}_{3}\right)$ methyl$\mathrm{COOH}-\mathrm{c}[\mathrm{RGDyK}]$, the fluorescence intensity decreased by $50 \%$, indicating that the length of the polymethine chain is related to dye stability.

Although the dyes and hybrid constructs all proved to be stable under nucleophilic attack, a 57\% decrease in absorbance and fluorescence signal in serum was seen for DTPA-Cy7-( $\left.\mathrm{SO}_{3}\right)$ methylCOOH-c[RGDyK] (Supplemental Figs. 5-7). No change in absorbance was seen for DTPA-Cy3-( $\left.\mathrm{SO}_{3}\right)$ methyl-COOH-c[RGDyK] or DTPA-Cy5-( $\left.\mathrm{SO}_{3}\right)$ methyl-COOH-c[RGDyK]. Regarding the fluorescence emission, the fluorescence of DTPA-Cy3- $\left(\mathrm{SO}_{3}\right)$ methyl$\mathrm{COOH}-\mathrm{c}[\mathrm{RGDyK}]$ was not altered, and only a $2 \%$ decrease in fluorescence signal was seen for DTPA-Cy5-( $\left.\mathrm{SO}_{3}\right)$ methyl-COOHc[RGDyK].

\section{Signal Penetration of Fluorescence Emissions}

The in-depth detectability of the dyes was studied using videorate recordings from a clinical-grade fluorescence laparoscope (Fig. 3B) $(29,30)$. Cy5-( $\left.\mathrm{SO}_{3}\right)$ methyl-COOH was shown to have signal penetration of up to $12 \mathrm{~mm}$ (as visibly detectable on screen). This visibility was superior to that of the near-infrared dyes Cy7-( $\left.\mathrm{SO}_{3}\right)$ methyl$\mathrm{COOH}(9 \mathrm{~mm})$ and ICG $(7.5 \mathrm{~mm}$; Supplemental Fig. 3B) and the dye Cy3-( $\left.\mathrm{SO}_{3}\right)$ methyl-COOH (detectable only when not covered by tissue).

\section{Receptor Affinity and Binding Localization}

With receptor affinities of $37.8 \pm 9 \mathrm{nM}$ for Cy3, $39.0 \pm 11 \mathrm{nM}$ for $\mathrm{Cy} 5$, and $48 \pm$ $9.5 \mathrm{nM}$ for Cy7, affinity for $\alpha_{\nu} \beta_{3}$ integrin was similar for all three hybrid tracers (Fig. 3C). Fluorescence confocal microscopy revealed that focal cytoplasmic uptake of DTPA-Cy3-( $\left.\mathrm{SO}_{3}\right)$ methyl-COOH-c[RGDyK] and DTPA-Cy5-( $\left.\mathrm{SO}_{3}\right)$ methyl-COOH-c [RGDyK] overlapped with the localization of lysosomes (Supplemental Fig. 8). Unfortunately, the Cy7 dye in DTPA-Cy7- $\left(\mathrm{SO}_{3}\right)$ methyl-COOH-c[RGDyK] could not be effectively excited by the lasers incorporated within the available microscopy setups (maximum excitation, $670 \mathrm{~nm}$ ), underlining the complexity of performing in vitro studies with near-infrared dyes.

\section{In Vivo Comparison of Biodistribution of ${ }^{111}$ In-DTPA-Cy3-c[RGDyK], \\ ${ }^{111}$ In-DTPA-Cy5-c[RGDyK], and ${ }^{111}$ In-DTPA-Cy7-c[RGDy]}

All three hybrid tracers enabled in vivo lesion discrimination using SPECT (Fig. 4A). Uptake of radioactivity in the tumor was $2.6 \pm$ $0.8,1.7 \pm 0.6$, and $5.2 \pm 0.5 \% \mathrm{ID} / \mathrm{g}$ for, respectively, ${ }^{111}$ In-DTPA-Cy3- $\left(\mathrm{SO}_{3}\right)$ methyl$\mathrm{COOH}-\mathrm{c}[\mathrm{RGDyK}], \quad{ }^{111}$ In-DTPA-Cy5$\left(\mathrm{SO}_{3}\right)$ methyl-COOH-c[RGDyK], and ${ }^{111}$ In-DTPA-Cy7-( $\left.\mathrm{SO}_{3}\right)$ methyl$\mathrm{COOH}-\mathrm{c}[\mathrm{RGDyK}]$. Together with the $\% \mathrm{ID} / \mathrm{g}$ uptake in the adjoining muscle tissue, a corresponding T/B ratio of $13.2 \pm 1.7$ was found for ${ }^{111}$ In-DTPA-Cy5-( $\left.\mathrm{SO}_{3}\right)$ methyl-COOH-c[RGDyK], $5.7 \pm 0.7$ for ${ }^{111}$ In-DTPA-Cy3-( $\left.\mathrm{SO}_{3}\right)$ methyl-COOH-c[RGDyK], and $4.7 \pm 0.7$ for ${ }^{111}$ In-DTPA-Cy7-(SO $\left.{ }_{3}\right)$ methyl-COOH-c[RGDyK] $(P<0.001$; Fig. 4B).

In vivo fluorescence imaging and fluorescence-based evaluation of the T/B ratio (Supplemental Fig. 9) revealed a comparable $\mathrm{Cy} 5>\mathrm{Cy} 3>\mathrm{Cy} 7$ trend, although with a greater difference between values $(10.89 \pm 1.2>1.28 \pm 0.3>0.99 \pm 0.6$, respectively; $P<0.001)$. These differences in T/B ratio agreed with the intraoperative visibility of the tumors using a laparoscopic setup (Fig. 4C).

Quantitative scoring of the relative performance of the $\mathrm{Cy} 3$ and Cy7 derivatives, compared with ${ }^{111}$ In-DTPA-Cy5-( $\left.\mathrm{SO}_{3}\right)$ methylCOOH-c[RGDyK] (Supplemental Tables 2 and 3), further underlined the superiority of the Cy5 derivate.

\section{DISCUSSION}

Underlining and extending previous reports that alterations in the pendant moieties on cyanine dyes affect tracer pharmacokinetics, the presented data reveal similar effects on tracer kinetics after the length of the polymethine chain was varied in cyanine dyes with identical pendant moieties. This finding provides yet another feature to consider when pursuing the utility of a tracer in fluorescence-guided surgery. 

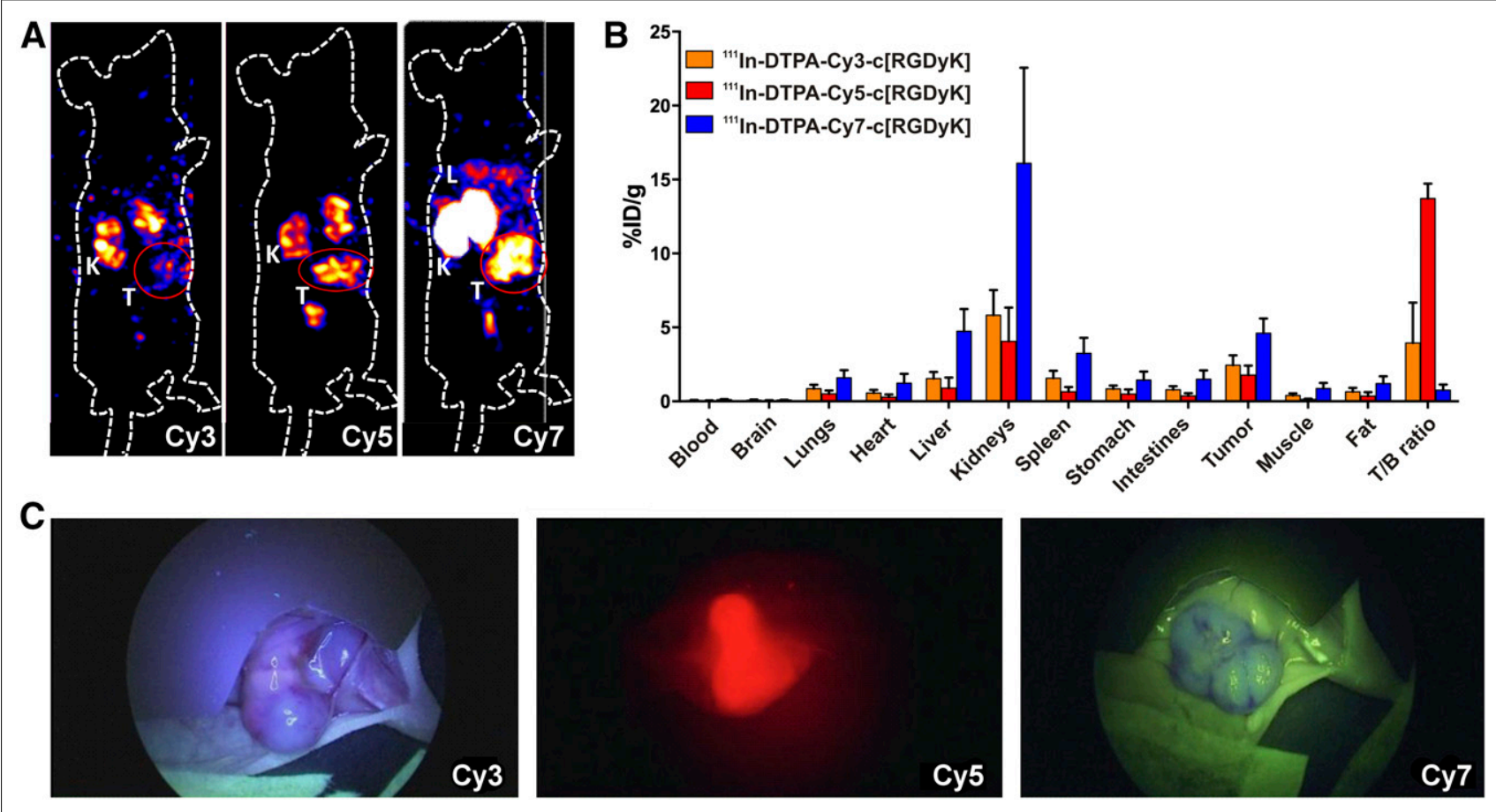

FIGURE 4. Comparison of in vivo biodistribution of hybrid $c[R G D y K]$ tracers with fluorescent components with polymethine chains of different

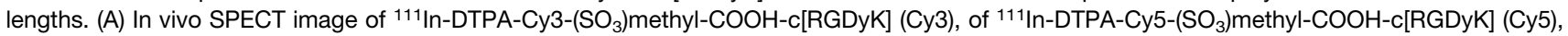
and of ${ }^{111} \mathrm{In}-\mathrm{DTPA}-\mathrm{Cy} 7-\left(\mathrm{SO}_{3}\right)$ methyl-COOH-c[RGDyK] (Cy7) at $24 \mathrm{~h}$ after tracer injection. $\mathrm{K}=$ kidney; $\mathrm{L}=$ liver; $\mathrm{T}=$ tumor (encircled in red). (B) Quantified biodistribution based on \%ID/g of excised tissue (radioactivity-based) for ${ }^{111} \mathrm{In}-\mathrm{DTPA}-\mathrm{Cy} 3-\left(\mathrm{SO}_{3}\right)$ methyl-COOH-c[RGDyK] (orange), ${ }^{111} \mathrm{In}-$ DTPA-Cy5-( $\left.\mathrm{SO}_{3}\right)$ methyl-COOH-c[RGDyK] (red), and ${ }^{111} \mathrm{In}-\mathrm{DTPA}-\mathrm{Cy} 3-\left(\mathrm{SO}_{3}\right)$ methyl-COOH-c[RGDyK] (blue). Determination of T/B was based on $\% \mathrm{ID} / \mathrm{g}$ in tumor and adjoining muscle tissue. (C) Accompanying in vivo fluorescence images obtained using clinical-grade fluorescence camera at 2-cm distance. Imaging and biodistribution analyses were performed at $24 \mathrm{~h}$ after injection. Images obtained with preclinical fluorescence scanner are provided in Supplemental Fig. 9.

Alteration of the length of the polymethine chain in otherwise identical cyanine dyes affected many features. The influence of alteration on rotational freedom around the polymethine bond within the cyanine dye (41) was reflected by variation in the photophysical properties of both the unconjugated dyes and the hybrid c[RGDyK] tracers (Table 1; Supplemental Table 1; Supplemental Fig. 4). The five atoms in the polymethine chain of the Cy5 analog seemed to produce the optimal degree of freedom, resulting in the highest quantum yield and both good chemical stability and good optical stability.

The chemical variation among the dyes affected the interaction with albumin and serum, as revealed by differences in quantum yield (Fig. 3A; Table 1; Supplemental Table 1), but also altered the in vivo pharmacokinetics (Fig. 4), as is attributable to the differences in protein binding among the tracers. While overall binding to albumin increased the quantum yield of both the unconjugated dyes (Supplemental Table 1) and the hybrid constructs (Table 1), the degree of nonspecific tissue uptake increased with increasing levels of protein binding (Cy5 < Cy3 < Cy7; Figs. 3A and 3B) (15). Together, these findings underline that interaction of dye with albumin affects the biodistribution, bioactivity, and metabolism of a compound (42-44). However, as the level of protein binding of the Cy3 and $\mathrm{Cy} 7$ conjugates was shown to be highly similar, the difference in biodistribution between these tracers cannot be solely explained through this interaction. The increased dye lipophilicity of $\mathrm{Cy} 7$ compared with $\mathrm{Cy} 3$ (Table 1; Supplemental
Table 1), however, seems to reveal an amplifying effect on the level of nonspecific uptake (45).

The hybrid nature of the tracers allowed imaging using both radioactivity and fluorescence, as well as quantitative \% ID/g assessments using radioactivity (Fig. 4; Supplemental Fig. 9; Supplemental Tables 2 and 3) (46,47). Interestingly, whereas radioactivity-based assessment revealed a 2.3 - to 2.8 -fold higher $\mathrm{T} / \mathrm{B}$ ratio for ${ }^{111} \mathrm{In}$-DTPA-Cy5-( $\left.\mathrm{SO}_{3}\right)$ methyl-COOH-c[RGDyK] than for the $\mathrm{Cy} 3$ and $\mathrm{Cy} 7$ derivatives (Fig. 4B), fluorescence-based assessment revealed an 8.4- to 9.1-fold higher ratio (Supplemental Fig. 9); only the Cy5 analog yielded a T/B of more than 2 . The 3 -fold difference between improvements determined using a radioactive readout and improvements determined using a fluorescence readout seems to be related to a combination of the superior brightness of the Cy5 dye (Table 1; Supplemental Table 1), the tissue penetration of the Cy5 fluorescence signal (Fig. 3B), and the compatibility of this dye with the fluorescence imaging modality used. The ability to sensitively detect $\mathrm{Cy} 5$ and $\mathrm{Cy} 7$ with the prototype Karl Storz fluorescence laparoscope (48) provides a promising extension of its previously proven ability to image fluorescein and ICG in a clinical setting ([29]).

In addition to the analysis steps described above, translation from molecule to man also favors the use of $\mathrm{Cy} 5$, because such far-red dyes are compatible with preclinical flow cytometers, fluorescence (confocal) microscopes, and clinical and preclinical fluorescence imaging systems (Fig. 3C; Supplemental Figs. 8 and 9B) (47). A lack of compatibility of near-infrared dyes with, for 
example, common confocal microscopes can be considered a limiting factor during the in vitro stages of tracer evaluation.

Combined, the reported findings advocate careful selection of dye during the development of receptor-targeted fluorescenceguided surgery applications. The fact that modest chemical variation induces significant effects on tracer performance also underlines the assumption that there is no such thing as a one-dyesuits-all solution to cover the complexity and plurality of targeting vectors explored for image-guided surgery (18). Our findings also underline the need for accurate (and quantitative) analysis of tracer pharmacokinetics, something that is made possible using hybrid tracer designs. Given the clinical potential demonstrated by hybrid tracers such as ICG-99m Tc-nanocolloid (10,46,49-51), adhering to such designs may also help improve clinical tracer implementation in image-guided surgery trials.

\section{CONCLUSION}

The length of the polymethine chain in cyanine dyes exerts a direct influence on the chemical, photophysical, and biologic properties of a tracer. In a c[RGDyK]-based model, the Cy5 analog proved to be superior to the $\mathrm{Cy} 3$ (visible fluorescence) and $\mathrm{Cy} 7$ (near-infrared fluorescence) analogs in all respects.

\section{DISCLOSURE}

This research was financially supported by STW-VIDI grant BGT11272 from the Netherlands Organization for Scientific Research, grant 2012-306890 from the European Research Council under the European Union's Seventh Framework Program (FP7/ 2007-2013), and the 2015-2016 Post-Doctoral Molecular Imaging Scholar Program Grant from the Society of Nuclear Medicine and Molecular imaging and the Education and Research Foundation for Nuclear Medicine and Molecular Imaging. No other potential conflict of interest relevant to this article was reported.

\section{REFERENCES}

1. Tjalma JJ, Garcia-Allende PB, Hartmans E, et al. Molecular fluorescence endoscopy targeting vascular endothelial growth factor A for improved colorectal polyp detection. J Nucl Med. 2016;57:480-485.

2. Oliveira S, Cohen R, Walsum MS, et al. A novel method to quantify IRDye800CW fluorescent antibody probes ex vivo in tissue distribution studies. EJNMMI Res. 2012;2:50.

3. Burggraaf J, Kamerling IM, Gordon PB, et al. Detection of colorectal polyps in humans using an intravenously administered fluorescent peptide targeted against c-Met. Nat Med. 2015;21:955-961.

4. de Boer E, Warram JM, Tucker MD, et al. In vivo fluorescence immunohistochemistry: localization of fluorescently labeled cetuximab in squamous cell carcinomas. Sci Rep. 2015;5:10169.

5. Gaykema SB, Brouwers AH, Lub-de Hooge MN, et al. ${ }^{89} \mathrm{Zr}$-bevacizumab PET imaging in primary breast cancer. J Nucl Med. 2013;54:1014-1018.

6. van Dam GM, Themelis G, Crane LM, et al. Intraoperative tumor-specific fluorescence imaging in ovarian cancer by folate receptor-alpha targeting: first inhuman results. Nat Med. 2011;17:1315-1319.

7. van Leeuwen FW, Valdes-Olmos R, Buckle T, Vidal-Sicart S. Hybrid surgical guidance based on the integration of radionuclear and optical technologies. $\mathrm{Br} \mathrm{J}$ Radiol. 2016;89:20150797.

8. Banerjee SR, Byun Y, Nimmagadda S, et al. Sequential SPECT and optical imaging of experimental models of prostate cancer with a dual modality inhibitor of the prostate-specific membrane antigen. Angew Chem Int Ed Engl. 2011;50:9167-9170.

9. Boonstra MC, van Driel PB, van Willigen DM, et al. uPAR-targeted multimodal tracer for pre- and intraoperative imaging in cancer surgery. Oncotarget. 2015;6: 14260-14273.

10. Brouwer OR, van den Berg NS, Matheron HM, et al. A hybrid radioactive and fluorescent tracer for sentinel node biopsy in penile carcinoma as a potential replacement for blue dye. Eur Urol. 2014;65:600-609.
11. Kuil J, Buckle T, Oldenburg J, et al. Hybrid peptide dendrimers for imaging of chemokine receptor 4 (CXCR4) expression. Mol Pharm. 2011;8:2444-2453.

12. Kuil J, Velders AH, van Leeuwen FW. Multimodal tumor-targeting peptides functionalized with both a radio- and a fluorescent label. Bioconjug Chem. 2010;21:1709-1719.

13. Lin X, Xie J, Zhu L, et al. Hybrid ferritin nanoparticles as activatable probes for tumor imaging. Angew Chem Int Ed Engl. 2011;50:1569-1572.

14. Baum RP, Kulkarni HR, Muller D, et al. First-in-human study demonstrating tumor-angiogenesis by PET/CT imaging with ${ }^{68} \mathrm{Ga}$-NODAGA-THERANOST, a high-affinity peptidomimetic for alphavbeta3 integrin receptor targeting. Cancer Biother Radiopharm. 2015;30:152-159.

15. Bunschoten A, Buckle T, Visser NL, et al. Multimodal interventional molecular imaging of tumor margins and distant metastases by targeting alphavbeta3 integrin. ChemBioChem. 2012;13:1039-1045.

16. Cai W, Chen X. Multimodality molecular imaging of tumor angiogenesis. $\mathrm{J} \mathrm{Nucl}$ Med. 2008;49(suppl 2):113S-128S.

17. Park JA, Kim JY, Lee YJ, et al. Gadolinium complex of ${ }^{125} \mathrm{I}^{127} \mathrm{I}$-RGD-DOTA conjugate as a tumor-targeting SPECT/MR bimodal imaging probe. ACS Med Chem Lett. 2012;4:216-219.

18. Bunschoten A, van Willigen DM, Buckle T, et al. Tailoring fluorescent dyes to optimize a hybrid RGD-tracer. Bioconjug Chem. 2016;27:1253-1258.

19. Choi HS, Gibbs SL, Lee JH, et al. Targeted zwitterionic near-infrared fluorophores for improved optical imaging. Nat Biotechnol. 2013;31:148-153.

20. Debie P, Van Quathem J, Hansen I, et al. Effect of dye and conjugation chemistry on the biodistribution profile of near-infrared-labeled nanobodies as tracers for image-guided surgery. Mol Pharm. 2017;14:1145-1153.

21. Ye Y, Bloch S, Kao J, Achilefu S. Multivalent carbocyanine molecular probes: synthesis and applications. Bioconjug Chem. 2005;16:51-61.

22. Zhou Y, Kim YS, Milenic DE, Baidoo KE, Brechbiel MW. In vitro and in vivo analysis of indocyanine green-labeled panitumumab for optical imaging: a cautionary tale. Bioconjug Chem. 2014;25:1801-1810.

23. Ogawa M, Kosaka N, Choyke PL, Kobayashi H. In vivo molecular imaging of cancer with a quenching near-infrared fluorescent probe using conjugates of monoclonal antibodies and indocyanine green. Cancer Res. 2009;69:1268-1272.

24. Verbeek FP, van der Vorst JR, Tummers QR, et al. Near-infrared fluorescence imaging of both colorectal cancer and ureters using a low-dose integrin targeted probe. Ann Surg Oncol. 2014;21(suppl 4):S528-S537.

25. Choi HS, Nasr K, Alyabyev S. Fet al. Synthesis and in vivo fate of zwitterionic near-infrared fluorophores. Angew Chem Int Ed Engl. 2011;50:6258-6263.

26. Hyun H, Owens EA, Narayana L, et al. Central C-C bonding increases optical and chemical stability of near-infrared fluorophores. RSC Advances. 2014;4:58762-58768.

27. van der Wal SKJ, Valentijn ARPM, van Leeuwen FWB. Synthesis and systematic evaluation of symmetric sulfonated centrally $\mathrm{Ce} C$ bonded cyanine nearinfrared dyes for protein labeling. Dyes Pigments. 2016;132:7-19.

28. Chin PT, Beekman CA, Buckle T, Josephson L, van Leeuwen FW. Multispectral visualization of surgical safety-margins using fluorescent marker seeds. Am J Nucl Med Mol Imaging. 2012;2:151-162.

29. van den Berg NS, Buckle T, KleinJan GH, van der Poel HG, van Leeuwen FW. Multispectral fluorescence imaging during robot-assisted laparoscopic sentinel node biopsy: a first step towards a fluorescence-based anatomic roadmap. Eur Urol. 2017;72:110-117.

30. van Willigen DM, van den Berg NS, Buckle T, et al. Multispectral fluorescence guided surgery: a feasibility study in a phantom using a clinical-grade laparoscopic camera system. Am J Nucl Med Mol Imaging. 2017;7:138-147.

31. Stummer W, Pichlmeier U, Meinel T, et al. Fluorescence-guided surgery with 5aminolevulinic acid for resection of malignant glioma: a randomised controlled multicentre phase III trial. Lancet Oncol. 2006;7:392-401.

32. Volpi D, Tullis IDC, Laois A, et al. A novel multiwavelength fluorescence image-guided surgery imaging system. In: Vo-Dinh T, Mahadevan-Jansen A, Grundfest WS, eds. Advanced Biomedical and Clinical Diagnostic Systems XII. Bellingham, WA: SPIE; 2014:8935.

33. Grimm JB, Muthusamy AK, Liang Y, et al. A general method to fine-tune fluorophores for live-cell and in vivo imaging. Nat Methods. 2017;14:987-994.

34. Lopalco M, Koini EN, Cho JK, Bradley M. Catch and release microwave mediated synthesis of cyanine dyes. Org Biomol Chem. 2009;7:856-859.

35. Shershov VE, Spitsyn MA, Kuznetsova VE, et al. Near-infrared heptamethine cyanine dyes. Synthesis, spectroscopic characterization, thermal properties and photostability. Dyes Pigments. 2013;97:353-360.

36. Spa SJ, Hensbergen AW, van der Wal S, Kuil J, van Leeuwen FWB. The influence of systematic structure alterations on the photophysical properties and conjugation characteristics of asymmetric cyanine 5 dyes. Dyes Pigments. 2018;152: 19-28.

37. Jiang L, Li B, Lv F, Dou L, Wang L. Synthesis of PEG derivatives bearing aminophenyl and their application for liquid-phase synthesis of water-soluble unsymmetrical cyanine dyes. Tetrahedron. 2009;65:5257-5264. 
38. Texier I, Goutayer M, Da Silva A, et al. Cyanine-loaded lipid nanoparticles for improved in vivo fluorescence imaging. J Biomed Opt. 2009;14: 054005 .

39. van Oosterom MN, Kreuger R, Buckle T, et al. U-SPECT-BioFluo: an integrated radionuclide, bioluminescence, and fluorescence imaging platform. EJNMMI Res. 2014;4:56.

40. Stennett EM, Ciuba MA, Levitus M. Photophysical processes in single molecule organic fluorescent probes. Chem Soc Rev. 2014;43:1057-1075.

41. Levitus M, Ranjit S. Cyanine dyes in biophysical research: the photophysics of polymethine fluorescent dyes in biomolecular environments. $Q$ Rev Biophys. 2011;44:123-151.

42. Bunschoten A, Buckle T, Kuil J, et al. Targeted non-covalent self-assembled nanoparticles based on human serum albumin. Biomaterials. 2012;33:867-875.

43. Neumann E, Frei E, Funk D, et al. Native albumin for targeted drug delivery. Expert Opin Drug Deliv. 2010;7:915-925.

44. Tesseromatis $\mathrm{C}$, Alevizou A. The role of the protein-binding on the mode of drug action as well the interactions with other drugs. Eur J Drug Metab Pharmacokinet. 2008;33:225-230.

45. Zhang L, Bhatnagar S, Deschenes E, Thurber GM. Mechanistic and quantitative insight into cell surface targeted molecular imaging agent design. Sci Rep. 2016;6:25424.
46. Brouwer OR, Buckle T, Vermeeren L, et al. Comparing the hybrid fluorescentradioactive tracer indocyanine green- ${ }^{99 \mathrm{~m}} \mathrm{Tc}$-nanocolloid with ${ }^{99 \mathrm{~m}} \mathrm{Tc}$-nanocolloid for sentinel node identification: a validation study using lymphoscintigraphy and SPECT/CT. J Nucl Med. 2012;53:1034-1040.

47. Buckle T, Kuil J, van den Berg NS, et al. Use of a single hybrid imaging agent for integration of target validation with in vivo and ex vivo imaging of mouse tumor lesions resembling human DCIS. PLoS One. 2013;8:e48324.

48. KleinJan GH, Bunschoten A, van den Berg NS, et al. Fluorescence guided surgery and tracer-dose, fact or fiction? Eur J Nucl Med Mol Imaging. 2016;43: 1857-1867.

49. Mathéron HM, van den Berg NS, Brouwer OR, et al. Multimodal surgical guidance towards the sentinel node in vulvar cancer. Gynecol Oncol. 2013;131:720-725.

50. Paredes P, Vidal-Sicart S, Campos F, et al. Role of ICG- ${ }^{99 \mathrm{~m}}$ Tc-nanocolloid for sentinel lymph node detection in cervical cancer: a pilot study. Eur J Nucl Med Mol Imaging. 2017;44:1853-1861.

51. Stoffels I, Leyh J, Poppel T, Schadendorf D, Klode J. Evaluation of a radioactive and fluorescent hybrid tracer for sentinel lymph node biopsy in head and neck malignancies: prospective randomized clinical trial to compare ICG- ${ }^{99 m} \mathrm{Tc}-$ nanocolloid hybrid tracer versus ${ }^{99 \mathrm{~m}}$ Tc-nanocolloid. Eur J Nucl Med Mol Imaging. 2015;42:1631-1638.

\section{Erratum}

In the article "Prostate Cancer Molecular Imaging Standardized Evaluation (PROMISE): Proposed miTNM Classification for the Interpretation of PSMA-Ligand PET/CT" by Eiber et al. ( Nucl Med. 2018;59:469-478), Table 2 contains two errors in the first column. miN1a should be miN1, and miN1b should be miN2. The authors regret the error. 